\title{
Sertraline enhances the activity of antimicrobial agents against pathogens of clinical relevance
}

\author{
Muhammad Ayaz ${ }^{1 *}$, Fazal Subhan², Jawad Ahmed ${ }^{3}$, Arif-ullah Khan ${ }^{4}$, Farhat Ullah ${ }^{1}$, Ihsan Ullah ${ }^{5}$, Gowhar Ali, \\ Nawazish-i-Husain Syed ${ }^{6}$ and Sajid Hussain ${ }^{7}$
}

\begin{abstract}
Background: Serotonin reuptake inhibitors were recently reported to possess antimicrobial potentials, potentiate activity of several antibiotics, reverse multidrug resistant phenotypes of bacteria and make them susceptible to previously resistant drugs. We investigated antimicrobial potentials of sertraline (SR) against ATCC strains, clinical isolates of Staphylococcus aureus, Escherichia coli and Pseudomonas aeruginosa alone and in-combination with seven antibiotics. Antifungal activity was investigated against four fungal strains including Aspergillus niger, Aspergillus fumigatus, Aspergillus flavus, and Fusarium solani. Intrinsic antibacterial action and Minimum Inhibitory Concentrations (MICs) were determined using well assay, nutrient broth and agar dilution techniques. Disk diffusion and nutrient broth methods were used to study bacterial susceptibility to SR. Minimum Fungicidal Concentrations (MFCs) of SR were determined using Sabouraud dextrose Agar (SDA).

Results: Sertraline possesses strong intrinsic antibacterial, antifungal activities and has augmented the antibacterial activities of antibiotics. For S. aureus ATCC 6538, E. coli ATCC 8739 and P. aeruginosa ATCC 9027, the MICs of SR were 20, 40 and $60 \mathrm{\mu g} \mathrm{ml}^{-1}$, respectively, whereas $55.5 \%$ clinical isolates of S. aureus and $50 \%$ of $E$. coli strains were inhibited at 20 and $60 \mathrm{\mu g} \mathrm{ml}^{-1}$ of SR, respectively. Among the tested fungi, $60 \%$ of A. niger and A. fumigatus were inhibited at 40 and $80 \mathrm{mg} \mathrm{ml}^{-1}$, respectively. MFCs were 60 and $80 \mathrm{\mu g} \mathrm{ml}^{-1}$ for A. flavus and F. solani, respectively. Antibacterial activities of all antibiotics were significantly increased $(p<0.001)$ with the addition of SR $100 \mathrm{\mu g} \mathrm{m}^{-1}$ against all tested bacteria.
\end{abstract}

Conclusion: Combination study revealed that SR had significantly increased the activity of antibiotics, and some previously resistant strains were made susceptible. Thus antidepressants are potential sources of resistance modifying agents when used in combination.

Keywords: Sertraline, Well assay, Minimum fungicidal concentration, ATCC

\section{Background}

The origin of chemo-resistance is multifactorial and is primarily based on imprudent utilization, sustained over reliance on antimicrobial agents, target site modification and active drug efflux mediated by efflux pumps. To triumph over multidrug resistance (MDR), one strategy is the use of inhibitors of resistance mechanisms having the ability to augment the efficacy of existing chemotherapeutic agents. Based on this idea, antimicrobial drugs are coadministered with an efflux pump inhibitor (EPI) that will neutralize the acquired resistance and the drug will be still effective even against resistant microorganisms [1]. Other

\footnotetext{
* Correspondence: ayazuop@gmail.com

${ }^{1}$ Department of Pharmacy, University of Malakand, Khyber Pakhtoonkhwa 18000, Pakistan

Full list of author information is available at the end of the article
}

strategies include the use of antibiotic inactivating enzymes inhibitors, i.e. amoxicillin plus clavulanic acid [2] and inhibitors of efflux pumps [3,4].

A large number of compounds used in the management of non-infectious pathological conditions like inflammation, depression and cardiovascular diseases are known to exhibit antimicrobial activities and called non-antibiotics [5]. Various studies on the antimicrobial activities of non-antibiotic compounds including antidepressants [6,7], antipsychotic $[8,9]$, antihypertensive [10], antihistaminics [11], antispasmodics [12], anti-inflammatory [13] and cardiovascular drugs [14] have been reported. In the presence of phenothiazines, including chlorpromazine and thioridazine in a culture medium, bacteria previously resistant to antimicrobial agents were shown to become susceptible $[8,15]$. More recently, it was suggested that chlorpromazine has decreased 
ethidium bromide efflux against all species of Salmonella enterica, Mycobacterium avium and Mycobacterium smegmatis [16,17]. Verapamil, a calcium channel blocker, has been reported to inhibit several bacterial efflux pumps including $p$-glycoprotein $[18,19]$. An anti-inflammatory drug diclofenac sodium was reported to possess remarkable antimicrobial properties against clinical isolates of bacteria [20]. Antidepressant drugs including selective serotonin reuptake inhibitors (SSRIs) have been extensively studied for their antimicrobial properties by several groups of researchers [6,21]. Kaatz et al. (2003) ivestigated antibacterial activities of paroxetine, femoxetine and their derivatives against E. coli, S. aureus and concluded that these compounds inhibit the activity of NorA, non-NorA and resistance nodulation division (RND) efflux pumps [22]. Similarly the antimicrobial properties of two tricyclic antidepressants imipramine, amitriptyline and phenothiazines were investigated by Hendricks et al. (2003) against Klebsiella pneumoniae, Staphylococcus aureus and Pseudomonas aeruginosa reported that these compounds exhibit excellent inhibitory effects against these bacteria [23]. Antidepressant drugs including fluoxetine, paroxetine, citalopram, and reboxetine have also been investigated by Lass-Flörl et al. for their antifungal properties against Candida parapsilosis, Aspergillus fumigatus, Aspergillus terreus, Aspergillus flavus and concluded these compounds inhibit the growth of all selected fungal strains and also posses inhibitory effect on replication of HIV [24,25].

Based on these evidences some antidepressants including sertraline (SR), citalopram (CIT) and venlafaxine (VF) were selected to uncover their potential antimicrobial characteristics alone, in-combination with antibiotics and effect of antidepressants-antibiotic combinations on resistance to these antibiotics. These antidepressants were also screened for antifungal potential against four pathogenic fungal strains. Among these drugs, SR was most potent regarding its minimum inhibitory concentration and intrinsic antibacterial activity and was further studied in combination with antibiotics.

\section{Results}

Intrinsic antibacterial assay of sertraline

Using agar dilution and well assay methods for determination of intrinsic antibacterial activity of SR against $S$. aureus, DIZ were increased with the increasing concentrations of SR. DIZ were found to be 8.5, 12, 14, 17, 20 and $26 \mathrm{~mm}$ for $10,20,40,60,80$ and $100 \mu \mathrm{g} \mathrm{ml}^{-1}$ of SR, respectively (Figure 1A). SR was found to possess strong antibacterial activity against $E$. coli 8739 . SR in concentrations of $10,20,40,60,80$ and $100 \mu \mathrm{g} \mathrm{ml}$ scored mean inhibitory zones $(n=3)$ of $5,6,8,11.5,15$ and $19 \mathrm{~mm}$ diameter, respectively against E. coli 8739 (Figure 1B). Similarly, the mean diameter of inhibitory
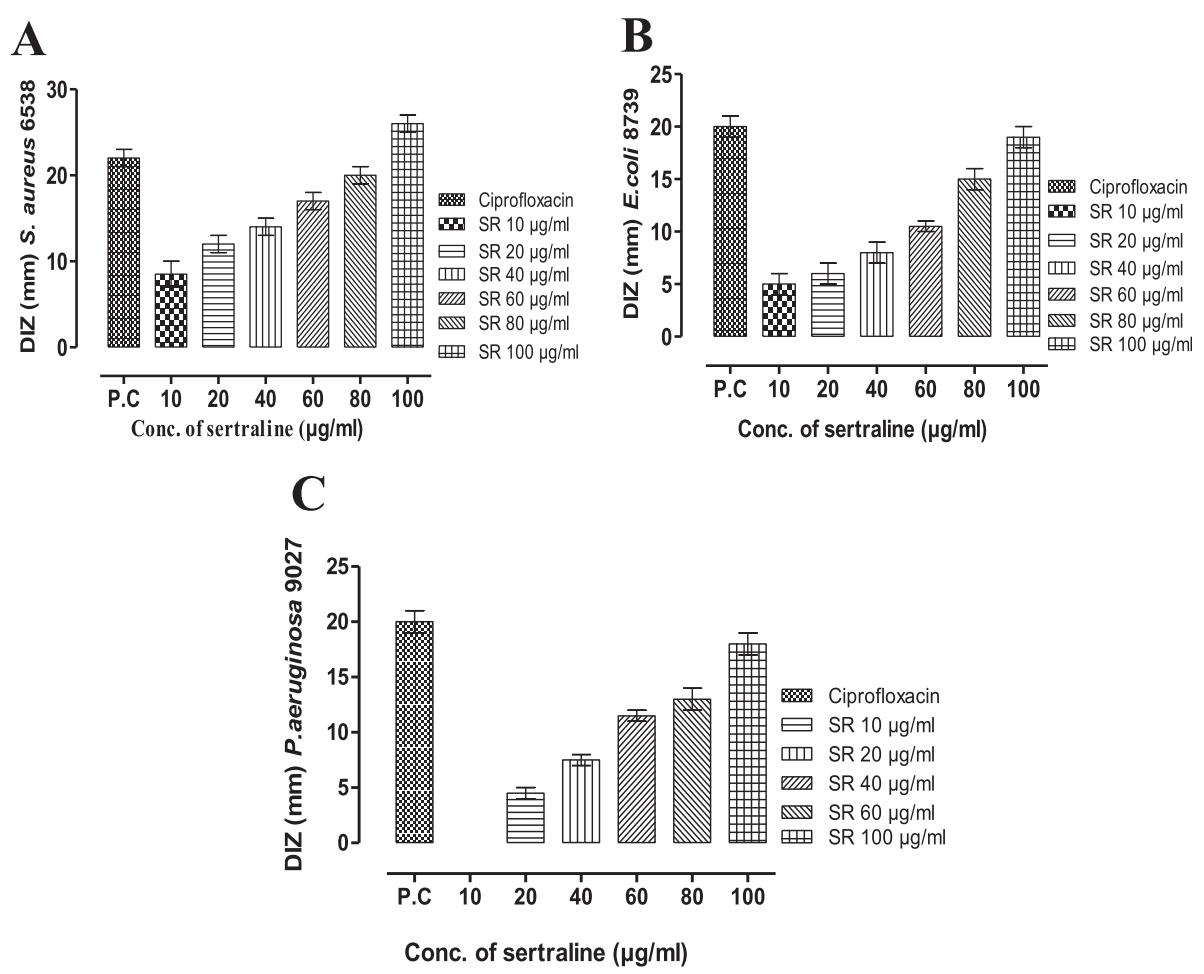

Figure 1 Intrinsic antibacterial effect of sertraline against S. aureus ATCC 6538 (A), E. coli ATCC 8739 (B) and P. aeruginosa ATCC 9027 (C), measured as diameter of inhibitory zone (DIZ) in comparison to positive control (Ciprofloxacin). DIZ (Diameter of inhibitory zone). 
zones of SR against $P$. aeruginosa was found to be $0,4.5$, $7.5,11,13$ and $18 \mathrm{~mm}$, respectively, against the same concentration of SR (Figure 1C).

Minimum antibacterial and antifungal concentrations MICs of SR against 28 bacterial strains including 3 ATCC, 25 clinical isolates and 13 fungal strains were studied. For ATCC strains (S. aureus ATCC 6538, E. coli ATCC 8739 and $P$. aeruginosa ATCC 9027), MICs of SR were 20,40 and $60 \mu \mathrm{g} \mathrm{ml}^{-1}$, respectively. Regarding the clinical isolates including $S$. aureus, 22\% (2/9) were inhibited at $10 \mu \mathrm{g} \mathrm{ml} \mathrm{g}^{-1}, 55.5 \%$ (5/9) were inhibited at $20 \mu \mathrm{g} \mathrm{ml}^{-1}$ and $11 \%(1 / 9)$ were inhibited at 40 and $60 \mu \mathrm{g} \mathrm{ml} \mathrm{m}^{-1}$ of SR, respectively. In clinical isolates of $E$. coli, $18.75 \%(3 / 16)$ strains were inhibited at $10 \mu \mathrm{g} \mathrm{m}{ }^{-1}$, $12.5 \%(2 / 16)$ were inhibited at 20 and $40 \mu \mathrm{g} \mathrm{ml}^{-1}, 50 \%$ $(8 / 16)$ were inhibited at $60 \mu \mathrm{g} \mathrm{ml} \mathrm{m}^{-1}$ and $6.25 \%(1 / 16)$ were inhibited at $100 \mu \mathrm{g} \mathrm{ml}^{-1}$ of SR. For fungal strains, MFCs were $20(1 / 5), 40(3 / 5)$ and $80(1 / 5) \mu \mathrm{g} \mathrm{ml}^{-1}$ for $A$. niger, $80 \mu \mathrm{g} \mathrm{ml}^{-1}(3 / 5)$ and $100 \mu \mathrm{g} \mathrm{ml}^{-1}(2 / 5)$ for $A$. fumigatus, 60 and $80 \mu \mathrm{g} \mathrm{ml}^{-1}$ for A. flavus and $80 \mu \mathrm{g} \mathrm{ml}^{-1}$ for $F$. solani.

\section{Effect of increasing concentrations of sertraline on the susceptibility of S. aureus 6538}

Antibacterial studies of SR alone and in combination with antibiotics against S. aureus 6538 are summarized in Table 1. The Dunnett's multiple comparison test was applied for the comparison of positive control with the test groups and revealed that a significant increase in the susceptibility pattern of S. aureus 6538 was observed. Diameter of Inhibitory Zone (DIZ) for ciprofloxacin in the absence of SR was $21.50 \pm 0.70 \mathrm{~mm}$, which was increased with the addition of SR in a concentration dependent manner and with the addition of SR $60 \mu \mathrm{g} \mathrm{ml}$ ${ }^{-1}$ a significant increase $(p<0.05)$ in the inhibitory zone $(30 \pm 4.24 \mathrm{~mm})$ was observed. Likewise levofloxacin, norfloxacin and moxifloxacin exhibited significant synergy $(p<0.05)$ with SR at a concentration of SR $80 \mu \mathrm{g} \mathrm{ml}{ }^{-1}$ scoring inhibitory zones of $33 \pm 5.65 \mathrm{~mm}, 34.50 \pm$ $7.77 \mathrm{~mm}, 34.50 \pm 4.94 \mathrm{~mm}$, respectively. The antibacterial activity of gentamicin was significantly increased at relatively low concentration of SR, i.e. $40 \mu \mathrm{g} \mathrm{ml}{ }^{-1}$. Staphylococcus aureus 6538 resistance to cefixime and cloxacillin were not reversed at any concentration of SR being used.

\section{Effect of increasing concentrations of sertraline on the susceptibility of E. coli $\mathbf{8 7 3 9}$}

The DIZ for ciprofloxacin in the absence of SR was $20 \pm$ $1.41 \mathrm{~mm}$ which was increased significantly (23 \pm $1.41 \mathrm{~mm}, p<0.05)$ with the addition of $20 \mu \mathrm{g} \mathrm{ml}^{-1}$ of SR (Table 2). Susceptibility to antibiotics increases with the addition of SR in concentration dependent manner. Levofloxacin, norfloxacin, and gentamicin exhibited significant synergy $(p<0.05)$ with SR at $40 \mu \mathrm{g} \mathrm{ml}^{-1}$ scoring inhibitory zones of $22 \pm 0.50 \mathrm{~mm}, 25.50 \pm 0.70 \mathrm{~mm}$, and $29.5 \pm 0.70 \mathrm{~mm}$, respectively. Antibacterial effect of moxifloxacin against $E$. coli 8739 was significantly increased $(p<0.001)$ at $80 \mu \mathrm{g} \mathrm{ml}^{-1}$ with an inhibitory zone of $32 \pm$ $1.41 \mathrm{~mm}$. Escherichia coli 8739 was initially resistant to cefixime but at concentration of $80 \mu \mathrm{g} \mathrm{ml}^{-1}$ it was made susceptible with an inhibitory zone of $9.50 \pm 0.70 \mathrm{~mm}$. At still higher concentrations of SR susceptibility was further increased scoring an inhibitory zone of $13.50 \pm$ $2.12 \mathrm{~mm}$. Escherichia coli 8739 was resistant to cloxacillin and the resistance was not affected by increasing concentrations of SR.

\section{Effect of increasing concentrations of sertraline on the susceptibility of $P$. aeruginosa 9027}

Antibacterial effect of antibiotics was increased significantly against $P$. aeruginosa 9027 with the addition of increasing concentrations of SR. Results are summarized in Table 3. DIZ for all antibiotics increased with the addition of SR in a concentration dependent manner. DIZ for levofloxacin $(22 \pm 1.41 \mathrm{~mm})$, norfloxacin $(20 \pm 0.00 \mathrm{~mm})$ and moxifloxacin $(24 \pm 1.41 \mathrm{~mm})$ were significantly increased with the

Table 1 Antibacterial effect of antibiotics alone and in combination with sertraline (SR) against S. aureus 6538

\begin{tabular}{|c|c|c|c|c|c|c|c|}
\hline \multicolumn{8}{|c|}{ Diameter of the inhibitory zone $(\mathrm{mm})$ Mean \pm SEM $(n=5)$} \\
\hline Antibiotic & Control & $\begin{array}{l}\text { Antibiotic + SR } \\
10 \mu \mathrm{gl}^{-1}\end{array}$ & $\begin{array}{l}\text { Antibiotic + SR } \\
20 \mu \mathrm{g} \mathrm{m}^{-1}\end{array}$ & $\begin{array}{l}\text { Antibiotic + SR } \\
40 \mu \mathrm{gl}^{-1}\end{array}$ & $\begin{array}{l}\text { Antibiotic + SR } \\
60 \mu \mathrm{g} \mathrm{ml}^{-1}\end{array}$ & $\begin{array}{l}\text { Antibiotic + SR } \\
80 \mu \mathrm{gl}^{-1}\end{array}$ & $\begin{array}{l}\text { Antibiotic + SR } \\
100 \mu \mathrm{gl}^{-1}\end{array}$ \\
\hline Ciprofloxacin $5 \mu \mathrm{g}$ & $21.50 \pm 0.70$ & $22.25 \pm 0.50$ & $24 \pm 1.41$ & $29 \pm 1.40$ & $30 \pm 4.24^{*}$ & $37 \pm 2.82^{* *}$ & $39.5 \pm 2.12^{* *}$ \\
\hline Levofloxacin $5 \mu \mathrm{g}$ & $20.50 \pm 0.70$ & $21.70 \pm 0.00$ & $23 \pm 1.41$ & $25.50 \pm 0.70$ & $26.50 \pm 0.70$ & $33 \pm 5.65^{*}$ & $36.5 \pm 4.94^{* *}$ \\
\hline Norfloxacin $10 \mu \mathrm{g}$ & $16.50 \pm 0.70$ & $17.5 \pm 0.50$ & $20.50 \pm 2.12$ & $21 \pm 1.41$ & $24 \pm 1.41$ & $34.5 \pm 7.77^{*}$ & $36.5 \pm 7.77^{*}$ \\
\hline Moxifloxacin $5 \mu \mathrm{g}$ & $22 \pm 1.41$ & $22 \pm 0.00$ & $23 \pm 1.41$ & $26.50 \pm 0.70$ & $28.50 \pm 0.70$ & $34.50 \pm 4.94^{*}$ & $37.5 \pm 3.53^{* *}$ \\
\hline Cefexime $5 \mu \mathrm{g}$ & $0 \pm 0.00$ & $0 \pm 0.00$ & $0 \pm 0.00$ & $0 \pm 0.00$ & $0 \pm 0.00$ & $0 \pm 0.00$ & $0 \pm 0.00$ \\
\hline Cloxacillin 5 mg & $0 \pm 0.00$ & $0 \pm 0.00$ & $0 \pm 0.00$ & $0 \pm 0.00$ & $0 \pm 0.00$ & $0 \pm 0.00$ & $0 \pm 0.00$ \\
\hline Gentamicin10 $\mu \mathrm{g}$ & $21.50 \pm 0.70$ & $22.50 \pm 0.20$ & $24.5 \pm 0.70$ & $27.50 \pm 0.70^{* *}$ & $29 \pm 1.41^{* *}$ & $35 \pm 1.41^{* * *}$ & $36.5 \pm 0.7^{* * *}$ \\
\hline
\end{tabular}

Significantly different as compared to antibiotic treated group only: ${ }^{*} p<0.05,{ }^{* *} p<0.01,{ }^{* * *} p<0.001$. Each value represent the mean of five replicates ( $\mathrm{n}=5$ ). Control: Antibiotic treated group only. 
Table 2 Antibacterial effect of antibiotics alone and in combination with increasing concentrations of sertraline (SR) against $E$. coli 87

\begin{tabular}{|c|c|c|c|c|c|c|c|}
\hline \multirow[t]{2}{*}{ Antibiotic } & \multicolumn{7}{|c|}{ Diameter of the inhibitory zone $(\mathrm{mm})$ Mean \pm SEM $(n=5)$} \\
\hline & Control & $\begin{array}{l}\text { Antibiotic + SR } \\
10 \mathrm{\mu g} \mathrm{ml}^{-1}\end{array}$ & $\begin{array}{l}\text { Antibiotic + SR } \\
20 \mu \mathrm{g} \mathrm{ml}^{-1}\end{array}$ & $\begin{array}{l}\text { Antibiotic + SR } \\
40 \mu \mathrm{g} \mathrm{m}^{-1}\end{array}$ & $\begin{array}{l}\text { Antibiotic + SR } \\
60 \mathrm{\mu g} \mathrm{ml}^{-1}\end{array}$ & $\begin{array}{l}\text { Antibiotic + SR } \\
80 \mu \mathrm{g} \mathrm{ml}^{-1}\end{array}$ & $\begin{array}{l}\text { Antibiotic + SR } \\
100 \mu \mathrm{gl}^{-1}\end{array}$ \\
\hline Ciprofloxacin $5 \mu \mathrm{g}$ & $20 \pm 1.41$ & $21 \pm 00$ & $23 \pm 1.41^{*}$ & $23.5 \pm 0.70^{* *}$ & $30 \pm 0.00^{* * *}$ & $33.5 \pm 2.10^{* * *}$ & $39 \pm 1.41^{* * *}$ \\
\hline Levofloxacin $5 \mu \mathrm{g}$ & $18 \pm 1.41$ & $20 \pm 0.50$ & $21 \pm 0.00$ & $22 \pm 0.50^{*}$ & $25 \pm 0.00^{* *}$ & $29 \pm 0.00^{* * *}$ & $38 \pm 1.41^{* * *}$ \\
\hline Norfloxacin $10 \mu \mathrm{g}$ & $17 \pm 0.41$ & $17 \pm 0.00$ & $19.50 \pm 2.12$ & $25.50 \pm 0.70^{*}$ & $24.50 \pm 0.70^{* *}$ & $27.50 \pm 0.70^{* * *}$ & $35.50 \pm 0.70^{* * *}$ \\
\hline Moxifloxacin $5 \mu \mathrm{g}$ & $20.5 \pm 0.70$ & $21 \pm 0.12$ & $22.50 \pm 0.70$ & $27.50 \pm 0.70$ & $27.50 \pm 0.70$ & $32 \pm 1.41^{* * *}$ & $40.50 \pm 0.70^{* * *}$ \\
\hline Cefexime $5 \mu \mathrm{g}$ & $0 \pm 0.00$ & $0 \pm 0.00$ & $0 \pm 0.00$ & $0 \pm 0.00$ & $0 \pm 0.00$ & $9.50 \pm 0.70$ & $13.50 \pm 2.12$ \\
\hline Cloxacillin $5 \mu \mathrm{g}$ & $0 \pm 0.00$ & $0 \pm 0.00$ & $0 \pm 0.00$ & $0 \pm 0.00$ & $0 \pm 0.00$ & $0 \pm 0.00$ & $0 \pm 0.00$ \\
\hline Gentamicin $10 \mu \mathrm{g}$ & $23 \pm 2.82$ & $24 \pm 0.70$ & $25 \pm 2.82$ & $29.5 \pm 0.70^{*}$ & $31.50 \pm 0.70^{* *}$ & $34.50 \pm 0.70^{* *}$ & $41.50 \pm 0.70^{* * *}$ \\
\hline
\end{tabular}

Values significantly different as compared to antibiotic treated group only: ${ }^{*} p<0.05,{ }^{* *} p<0.01,{ }^{* * *} p<0.001$. Each value represent mean of five replicates ( $\mathrm{n}=5$ ). Control: Antibiotic treated group only.

addition of SR $40 \mu \mathrm{g} \mathrm{ml}{ }^{-1}$, SR $20 \mu \mathrm{g} \mathrm{ml}^{-1}$ and SR $60 \mu \mathrm{g} \mathrm{ml}^{-1}$ of SR respectively. Pseudomonas aeruginosa 9027 was completely resistant to cefixime and cloxacillin and addition of increasing concentrations of SR has not reversed this resistance. In the absence of SR the DIZ for gentamicin against $P$. aeruginosa 9027 was $24.50 \pm 0.70 \mathrm{~mm}$ which was increased significantly $(p<0.05)$ at concentration of SR $40 \mu \mathrm{g} \mathrm{ml}^{-1}$ of SR scoring an inhibitory zone of $29.50 \pm 0.70 \mathrm{~mm}$.

\section{Discussion}

Combination therapy with antimicrobial agents has become commonplace due to the emergence of multidrug resistant (MDR) pathogens [26,27]. One of the strategies is to develop drugs in combination, as synergistic interactions may potentially prevent the emergence of acquired resistance, can augment efficacy, decrease toxicity and provide broader spectrum of activity than monotherapy regimens. Previous studies demonstrated that the combination antimicrobial therapy is effective against difficult-to-treat diseases like tuberculosis and HIV infection, as these microbes do not respond to mono-therapy either due to emergence of resistance or lack of efficacy [28]. As combination drug therapy is a suitable model of additively, so such experiments can provide important insights into the significance of synergistic and antagonistic relations of a variety of compounds and antimicrobials [29]. In this regard, antibiotics and non-antibiotic combinations should be checked for possible synergistic or antagonistic interactions. Identification of such combinations might be beneficial for empirical use and can decrease the cost and duration of antimicrobial drug therapy. The motive for selecting SR for synergy studies was long term use and previous studies on antidepressants and antipsychotic drugs $[22,23,25]$. Our findings indicate that SR possess strong antibacterial and antifungal activities in vitro and some bacterial strains previously resistant to antibiotics were made susceptible with the addition of SR.

From the intrinsic antibacterial studies, it is evident that SR possesses antibacterial characteristics and inhibited bacterial growth at different concentrations. The antibacterial activity of SR was more prominent against gram positive bacteria, i.e. S. aureus as compared to gram negative. Diameter of inhibitory zones were increased significantly along the concentration of 10,20 , 40, 60, 80, $100 \mu \mathrm{g} \mathrm{ml}^{-1}$ and at still higher concentrations

Table 3 Antibacterial effect of sertraline (SR) and antibiotics combination against $P$. aeruginosa 9027

\begin{tabular}{|c|c|c|c|c|c|c|c|}
\hline \multicolumn{8}{|c|}{ Diameter of the inhibitory zone $(\mathrm{mm})$ Mean \pm SEM $(n=5)$} \\
\hline Antibiotic & Control & $\begin{array}{l}\text { Antibiotic + SR } \\
10 \mu \mathrm{gl}^{-1}\end{array}$ & $\begin{array}{l}\text { Antibiotic + SR } \\
20 \mu \mathrm{gl}^{-1}\end{array}$ & $\begin{array}{l}\text { Antibiotic + SR } \\
40 \mu \mathrm{gl}^{-1}\end{array}$ & $\begin{array}{l}\text { Antibiotic + SR } \\
60 \mu \mathrm{gl}^{-1}\end{array}$ & $\begin{array}{l}\text { Antibiotic + SR } \\
80 \mu \mathrm{gl}^{-1}\end{array}$ & $\begin{array}{l}\text { Antibiotic + SR } \\
100 \mu \mathrm{gl}^{-1}\end{array}$ \\
\hline Ciprofloxacin $5 \mu \mathrm{g}$ & $20 \pm 0.00$ & $20.8 \pm 0.20$ & $22 \pm 2.82$ & $26 \pm 2.82$ & $29 \pm 2.82^{*}$ & $33 \pm 2.82^{* *}$ & $40 \pm 2.82^{* * *}$ \\
\hline Levofloxacin $5 \mu \mathrm{g}$ & $22 \pm 1.41$ & $23.0 \pm 0.50$ & $24 \pm 1.41$ & $27 \pm 1.41^{*}$ & $30 \pm 1.41^{* *}$ & $37 \pm 1.41^{* * *}$ & $41 \pm 0.00^{* * *}$ \\
\hline Norfloxacin $10 \mu \mathrm{g}$ & $20 \pm 0.00$ & $21 \pm 0.70$ & $24.5 \pm 0.70^{* *}$ & $26.50 \pm 0.70^{* * *}$ & $30.50 \pm 0.70^{* * *}$ & $33.5 \pm 0.70^{* * *}$ & $39.5 \pm 0.70^{* * *}$ \\
\hline Moxifloxacin $5 \mu \mathrm{g}$ & $24 \pm 1.41$ & $24 \pm 0.50$ & $26 \pm 1.41$ & $28 \pm 1.41$ & $32 \pm 1.41^{* *}$ & $36 \pm 1.41^{* * *}$ & $42.5 \pm 0.70^{* * *}$ \\
\hline Cefexime $5 \mu \mathrm{g}$ & $0 \pm 0.00$ & $0 \pm 0.00$ & $0 \pm 0.00$ & $0 \pm 0.00$ & $0 \pm 0.00$ & $0 \pm 0.00$ & $0 \pm 0.00$ \\
\hline Cloxacillin $5 \mu \mathrm{g}$ & $0 \pm 0.00$ & $0 \pm 0.00$ & $0 \pm 0.00$ & $0 \pm 0.00$ & $0 \pm 0.00$ & $0 \pm 0.00$ & $0 \pm 0.00$ \\
\hline Gentamicin $10 \mu \mathrm{g}$ & $24.50 \pm 70$ & $25 \pm 0.50$ & $26.50 \pm 0.70$ & $29.50 \pm 0.70^{*}$ & $33.50 \pm 0.70^{* * *}$ & $38.50 \pm 0.70^{* * *}$ & $41.5 \pm 0.70^{* * *}$ \\
\hline
\end{tabular}

Values significantly different as compare to antibiotic treated group only: ${ }^{*} p<0.05,{ }^{* *} p<0.01,{ }^{* * *} p<0.001$. Control: Antibiotic treated group only. 
complete inhibition of bacterial growth was observed. Using nutrient broth, MIC study revealed that the most effective concentration of SR against $S$. aureus was $20 \mu \mathrm{g} \mathrm{ml}^{-1}$ at which majority of clinical isolates and ATCC strain were inhibited while $60 \mu \mathrm{g} \mathrm{ml}^{-1}$ was most effective against E.coli strains indicating its effectiveness against Gram positive bacteria. Antifungal study demonstrates that SR possess fungicidal properties and inhibited fungal growth at different concentrations. SR in a concentration of $80 \mu \mathrm{g} \mathrm{ml}^{-1}$ was most effective, at which majority of fungal strains were inhibited. Interestingly, majority of $A$. niger species were inhibited at relatively low concentration of SR, i.e. $40 \mu \mathrm{g} \mathrm{ml}^{-1}$. Previous studies indicated that chlorpromazine and its analogues possesses bactericidal, fungicidal, and antiprotozoal properties through enzymatic inhibition but the proposed bactericidal and fungicidal activities of SR is still to be uncovered [30]. However it has been reported that the antifungal activity of SR is probably due to interaction with the fungal membrane transport system [24] or through inhibition of extracellular phospholipase activity [25] leading to cell death.

During combination studies, synergy between antibiotics and non-antibiotic (SR) was observed. Antibiotics exhibited synergy with SR against $S$. aureus in a concentration dependent manner, and diameter of inhibitory zones were increased with the addition of increasing concentrations of SR. However Staphylococcus species showed resistance to cefixime and cloxacillin and with the addition of SR susceptibility to these antibiotics were not changed. Addition of SR at concentrations higher than $100 \mu \mathrm{g} \mathrm{ml}^{-1}$ with antibiotic has completely eradicated bacterial growth and as a result quantification of antibiotic-SR synergy at this concentration was not possible. The exact mechanism of antibacterial activity of SR is still not clear and will require molecular studies. We hypothesize that as SR is selective serotonin reuptake inhibitor (SSRI), a reuptake pump inhibitor in humans [31], so it can act as efflux pump inhibitor in bacteria. However, to confirm that antibacterial activity of SR is due to inhibition of efflux pump, use of bacteria with molecularly characterized efflux pumps and studies with known efflux pumps inhibitors like ethidium bromide will be required. In this regard further studies are in progress in our laboratory.

The inhibitory zones were increased in the same way for the selected antibiotics with the addition of increasing concentrations of SR against $E$. coli. Initially resistance to cefixime was observed however with the addition of increasing concentrations of SR E. coli species were converted to susceptible range. Increase in the antibacterial effect of antibiotics was sustained in the same manner for $P$. aeruginosa. However its resistance to cefixime and cloxacillin were not affected by addition of SR.
The human therapeutic dose of SR is $50-200 \mathrm{mg}$ daily [32], so the concentrations being used are very low as compared to minimum toxic concentrations and safety studies at high concentrations, i.e. $1300 \mu \mathrm{g} \mathrm{ml}^{-1}$ in experimental animals are already established [33]. From bioavailability point of view any relevance between our in vitro results and in vivo performance is still not clear and may require further in vivo studies to investigate the mechanism of SR induced bacterial and fungal death. However it is concluded that SR and other SSRIs are potential drugs for further characterization and development of new antimicrobial drugs. Further, while using SR for antimicrobial purpose, its systemic effects including neurological aspects especially at high doses must be determined. Further studies are required in this regard.

\section{Conclusions}

Sertraline (SR) possesses strong intrinsic antibacterial and antifungal activities. Combination study revealed that sertraline has significantly increased the antimicrobial effect of antibiotics, and some previously resistant strains were made susceptible. Further, SR is very effective at higher concentration but neurological effects at such higher concentration must be studied. Further derivatization and use of bacteria containing molecularly characterized efflux pumps can provide more convincing results.

\section{Methods \\ Chemicals and Drugs}

Sertraline (SR) was kindly provided by Wilshire Pharmaceuticals Lahore, Pakistan. Antibiotic powder of ciprofloxacin, levofloxacin, norfloxacin, moxifloxacin, cefixime, cloxacillin, and gentamicin, (Sigma Aldrich CHEMIE $\mathrm{GmbH}$ USA) were used in the study. Dimethyl-Sulfoxide (DMSO) (Labscan Patumwan Bankok 10330 Thialand), 99.9\% pure was used for dissolution of SR.

\section{Bacteria and fungi}

Gram positive, Gram negative and American Type Culture Collection (ATCC) strains of bacteria and fungal strains were used to uncover the antibacterial and antifungal potential of SR. Nine clinical isolates and one ATCC (6538) strain of $S$. aureus, 16 clinical isolates and one ATCC strain (8739) of $E$. coli, one ATCC strain of $P$. aeruginosa (9027), 13 fungal strains of $A$, niger, A. fumigatus, A. flavus, and $F$. solani were used in the study. Bacterial ATCC strains were provided by Cirin Pharmaceuticals Pakistan. Clinical isolates were collected from microbiology department of Khyber Teaching Hospital (KTH) Peshawar, Pakistan and were identified by different biochemical tests [34]. Bacteria were preserved in freezedried condition at $4^{\circ} \mathrm{C}$ in stab slant agar until later use. Fungal strains were provided by Microbiology Department 
Kohat University of Science and Technology (KUST) Kohat, Pakistan.

\section{Culture media}

Mueller-Hinton agar (MHA Oxoid UK), Mannitol salt agar, Mackonkey's Agar (Oxoid Ltd, England, CM0115), Triple sugar iron (TSI) agar (Oxoid Ltd, England, CM0277), Sabouraud's dextrose agar and nutrient broth base powder (Oxoid Ltd, England) were used in the study for culture and identification of microbes according to the guidelines of clinical laboratory standards institute (CLSI) and manufacturer specifications [35].

\section{Preparation of sertraline stock solutions}

SR is sparingly soluble in water so it was dissolved in DMSO and serial two fold dilutions of the drug were made, ranging from $10-100 \mu \mathrm{g} \mathrm{ml}^{-1}$ under laminar flow hood. Stock solutions and dilutions of the drugs were prepared according to CLSI recommendations and manufacturer's specifications [36,37].

\section{Standardization of bacterial and fungal suspensions}

Bacterial culture was grown for $24 \mathrm{hrs}$ at $37^{\circ} \mathrm{C}$ and suspension with cell density of $1 \times 10^{8} \mathrm{CFU} \mathrm{ml} \mathrm{m}^{-1}$, was prepared using McFarland standard and was further diluted to a cell density of $1 \times 10^{6} \mathrm{CFU} \mathrm{m}{ }^{-1}$ using a UV visible spectrophotometer (Thermo electron corporation, USA) at $625 \mathrm{~nm}$ and the standardization was maintained for the period of the study. Fungal strains were grown at $25^{\circ} \mathrm{C}$ and suspensions corresponding to $2.5 \times 10^{4}$ cells $\mathrm{ml}^{-1}$ were prepared by dilution in normal saline. Standardization of fungal strains were performed using microscopic enumeration with a cell-counting hematocytometer and optical density method as previously reported [38].

\section{Intrinsic antibacterial studies on sertraline}

Preliminary intrinsic antibacterial action of SR was determined using agar dilution and well assay methods. In agar dilution method, SR solutions corresponding to 10 , 20, 40, 5060,80 and $100 \mu \mathrm{g} \mathrm{ml}^{-1}$ were aseptically added to sterile molten MHA at $40^{\circ} \mathrm{C}$ [39]. One loopful of the already prepared bacterial suspension was inoculated on the MHA plates containing increasing concentration of SR. Plates were incubated at $37^{\circ} \mathrm{C}$ for $18-72 \mathrm{hrs}$ and were examined for the appearance of growth. In well assay method, bacterial plates were inoculated by swabbing MHA plates with already prepared bacterial suspensions under laminar flow hood [40-42]. Wells of $6 \mathrm{~mm}$ diameter were bored into the MHA plates using sterilized cork borer. After drying the bores were filled with $100 \mu \mathrm{L}$ solutions of different concentrations of SR and antibiotics taking care not to let spillage of the solutions on the surface of the agar. The plates were incubated at $37^{\circ} \mathrm{C}$ for $24 \mathrm{hrs}$. Zone of inhibition were measured around the bores and were compared with positive control ciprofloxacin.

\section{Determination of minimum inhibitory concentration (MICs)}

For determination of MICs both nutrient broth and agar dilution methods approved by national committee for clinical laboratory standards (NCCLS) were used $[43,44]$. For these tests, SR in concentration of 10, 20, 40, 5060 , 80 and $100 \mu \mathrm{g} \mathrm{ml}^{-1}$ were added to sterilized tube containing nutrient broth and were inoculated with the test microbes. Tubes were incubated using shaker incubator at $37^{\circ} \mathrm{C}$ for $24 \mathrm{hrs}$. MIC was considered that concentration at which no visible bacterial growth was observed. All experiments were done in three replicates.

\section{In vitro synergy between sertraline (SR) and antibiotics}

The combined antibacterial effect of SR and antibiotics was determined by disk diffusion method described by CLSI [45] and previously reported procedure by Dutta et al. [20]. Sterile filter paper disks (Whatman no. 1) $7.25 \mathrm{~mm}$ diameter were prepared. In combination study of SR and antibiotics, solutions corresponding to $5 \mu \mathrm{g}$ of ciprofloxacin, levofloxacin, moxifloxacin, cefexime, cloxacillin, $10 \mu \mathrm{g}$ of norfloxacin and gentamicin and 10$100 \mu \mathrm{g}$ of SR were added to these disks. Antibiotic disks of these drugs available were used as positive control. Overnight grown bacterial culture was used to prepare bacterial suspensions. From these suspension $100 \mu \mathrm{l}$ were uniformly spread over the surface of already prepared MHA plates under laminar flow hood and were allowed to dry. Disks containing antibiotic alone and increasing concentrations of SR were placed equidistantly on the surface of inoculated plated and were incubated at $37^{\circ} \mathrm{C}$ for $24 \mathrm{hrs}$. Diameter of inhibitory zones (DIZ) of antibiotic alone and in combination with SR was determined to CLSI standards for zone interpretation [46].

\section{Antifungal activities of sertraline}

Minimum fungicidal concentrations (MFC) of SR were determined using Sabouraud's dextrose agar (SDA). Briefly, Sabouraud's dextrose agar tubes were prepared according to manufacturer specifications and solutions of SR corresponding to 10, 20, 40, 5060,80 and $100 \mu \mathrm{g} \mathrm{ml}^{-1}$ were added to these tubes at $40^{\circ} \mathrm{C}$. The tubes were inoculated by adding one loopful of already prepared fungal suspensions and were incubated at $27^{\circ} \mathrm{C}$. After 7-10 days of incubation tubes were observed for fungal growth. MFC were considered the lowest concentration that inhibited fungal growth $\mathrm{nn}$. 


\section{Statistical analysis}

One-way ANOVA, followed Dunnett's multiple comparison test, were applied for the comparison of positive control with the test groups using GraphPad Prisim-5 (Software Inc., La Jolla, CA, USA). All the assays were repeated in triplicate and values were expressed as means \pm S.E.M. The $p$ values less than 0.05 were considered as statistically significant.

\section{Competing interests}

The authors declare that they have no competing interests.

\section{Authors' contributions}

MA carried out experimental work, data collection and evaluation, literature search and manuscript preparation. FS and JA supervised research work and guided in study design. AU, FU, IU, GA, NHS and SH refined the manuscript for publication. All authors read and approved the final manuscript for publication.

\section{Acknowledgements}

The authors sincerely thank Wilshire pharmaceuticals Lahore Pakistan for providing SR powder for research purpose. The authors are also grateful to Cirin Pharmaceuticals Pakistan and Microbiology Department Khyber Teaching Hospital (KTH), Peshawar, Pakistan for providing ATCC strains and Laboratory facilities.

\section{Author details}

${ }^{1}$ Department of Pharmacy, University of Malakand, Khyber Pakhtoonkhwa 18000, Pakistan. ${ }^{2}$ Department of Pharmacy, University of Peshawar, Peshawar, Pakistan. ${ }^{3}$ Institute of Basic Medical Sciences (IBMS), Khyber Medical University, Peshawar, Pakistan. ${ }^{4}$ Department of Pharmacology, Riphah Institute of Pharmaceutical Sciences, Riphah International University, Islamabad, Pakistan. ${ }^{5}$ Department of Pharmacy, University of Swabi, Swabi, Pakistan. ${ }^{6}$ University College of Pharmacy, University of The Punjab Lahore, Lahore 54000, Pakistan. ${ }^{7}$ Department of Pharmacy, Kohat University of Science and Technology, Kohat, Pakistan.

Received: 2 December 2014 Accepted: 7 April 2015

Published online: 16 April 2015

\section{References}

1. Wright GD. Resisting resistance: new chemical strategies for battling superbugs. Chem Biol. 2000;7:R127-R32.

2. Finlay J, Miller L, Poupard JA. A review of the antimicrobial activity of clavulanate. J Antimicrob Chemother. 2003;52:18-23.

3. Hajduk PJ, Dinges J, Schkeryantz JM, Janowick D, Kaminski M, Tufano M, et al. Novel inhibitors of Erm methyltransferases from NMR and paralle synthesis. J Med Chem. 1999;42:3852-9.

4. Gao Y. Glycopeptide antibiotics and development of inhibitors to overcome vancomycin resistance. Nat Prod Rep. 2002;19:100-7.

5. Kristiansen JE. The antimicrobial activity of non-antibiotics. APMIS 1992;100:7-14.

6. Munoz-Bellido JL, Munoz-Criado S, Garcia-Rodriguez JA. Antimicrobial activity of psychotropic drugs: selective serotonin reuptake inhibitors. Inter J Antimicrob Agents. 2000;14:177-80.

7. Kristiansen JE, Mortensen I, Gaarslev K. The antibiotic effect of the anti-depressive drug femoxetine and its stereo-isomeric analogs on diarrhoea producing enterobacteriaceae. Acta Pathol Microbiol Immunol Scand B. 1986;94:103-6.

8. Martínez-Martínez L, Cano EM, Rodríguez-Martínez MJ, Calvo J, Pascual A. Plasmid-mediated quinolone resistance. Expert Rev Anti Infect Ther. 2008;6:685-711.

9. Dastidar SG, Jairaj J, Mookerjee M, Chakrabarty AN. Studies on antimicrobial effect of the antihistaminic phenothiazine trimeprazine tartrate. Acta Microbiol Immunol Hung. 1997:44:241-7.

10. Dutta NK, Mazumdar K, DasGupta A, Dastidar SG. In vitro and in vivo efficacies of amlodipine against Listeria monocytogenes. Eur J Clin Microbiol Infect Dis. 2009;28:849-53.
11. Chattopadhyay D, Dastidar SG, Chakrabarty AN. Antimicrobial properties of methdilazine and its synergism with antibiotics and some chemotherapeutic agents. Arzneimittelforschung. 1988;38:869-72.

12. Karak P, Kumar KA, Mazumdar K, Mookerjee M, Dastidar SG. Antibacterial potential of an antispasmodic drug dicyclomine hydrochloride. Indian J Med Res. 2003;118:192-6.

13. Mazumdar K, Dastidar SG, Park JH, Dutta NK. The anti-inflammatory non-antibiotic helper compound diclofenac: an anti-bacterial drug target. Eur J Clin Microbiol Infect Dis. 2009;28:881-91.

14. Mazumdar K, Ganguly K, Kumar AK, Dutta NK, Chakrabarty AN, Dastidar SG. Antimicrobial potentiality of a new non-antibiotic: the cardiovascular drug oxyfedrine hydrochloride. Microbiol Res. 2003;158:259-64.

15. Strahilevitz J, Jacoby GA, Hooper DC, Robicsek A. Plasmid-mediated quinolone resistance: a multifaceted threat. Clin Microbiol Rev. 2009;22:664-89.

16. Rodrigues L, Wagner D, Viveiros M, Sampaio D, Couto I, Vavra M, et al. Thioridazine and chlorpromazine inhibition of ethidium bromide efflux in Mycobacterium avium and Mycobacterium smegmatis. J Antimicrob Chemother. 2008;61:1076-82

17. Bailey AM, Paulsen IT, Piddock LJV. RamA confers multidrug resistance in Salmonella enterica via increased expression of acrB, which is inhibited by chlorpromazine. Antimicrob Agents Ch. 2008:52(10):3604-11.

18. Choudhuri BS, Bhakta S, Barik R, Basu J, Kundu M, Chakrabati P. Overexpression and functional characterization of an ABC (ATP-binding cassette) transporter encoded by the genes drrA and drrB of Mycobacterium tuberculosis. Biochem J. 2002;367:279-85.

19. Lee EW, Huda MN, Kuroda T, Mizushima T, Tsuchiya T. EfrAB, an ABC multidrug efflux pump in Enterococcus faecalis. Antimicrob Agents Chemother. 2003:47:3733-8.

20. Dutta NK, Annadurai S, Mazumdar K, Dastidar SG, Kristiansen JE, Molnar J, et al. Potential management of resistant microbial infections with a novel non-antibiotic: the anti-inflammatory drug diclofenac sodium. Int J Antimicrob Agents. 2007;30:242-9.

21. Bohnert JA. Szymaniak-Vits M, Schuster S, Kern W. Efflux inhibition by selective serotonin reuptake inhibitors in Escherichia coli. J Antimicrob Chemother. 2011;66:2057-60.

22. Kaatz GW, Moudgal W, Seo SM, Hansen JB, Kristiansen JE. Phenylpiperidine selective serotonin reuptake inhibitors interfere with multidrug efflux pump activity in Staphylococcus aureus. Int J Antimicrob Agents. 2003;22(3):254-61.

23. Hendricks O, Butterworth TS, Kristiansen JE. The in-vitro antimicrobial effect of non-antibiotics and putative inhibitors of efflux pumps on Pseudomonas aeruginosa and Staphylococcus aureus. Int J Antimicrob Agents. 2003;22(3):262-4

24. Lass-Flörl C, Dierich MP, Fuchs D, Semenitz E, Jenewein I, Ledochowski M. Antifungal properties of selective serotonin reuptake inhibitors against Aspergillus species in vitro. J Antimicrob Chemother. 2001:48:775-9.

25. Lass-Flörl C, Ledochowski M, Fuchs D, Speth C, Kacani L, Dierich MP, et al. Interaction of sertraline with Candida species selectively attenuates fungal virulence in vitro. FEMS Immunol Med Microbiol. 2006;35:11-5.

26. Jawetz E. The use of combinations of antimicrobial drugs. Ann Rev Pharmacol. 1968;8:151-70.

27. Walsh C. Molecular mechanisms that confer antibacterial drug resistance. Nature. 2000;406:775-81.

28. Horsburgh CRJ, Feldman S, Ridzon R. Practice guidelines for the treatment of tuberculosis. Clin Infect Dis. 2000;31:633-9.

29. Berenbaum MC. Correlations between methods for measurement of synergy. J Infect Dis. 1980;142:476-80.

30. Amaral L, Viveiros M, Molnar J. Antimicrobial activity of phenothiazines. In vivo. 2004;18(6):725-32.

31. Martin J. BNF 57 March 2009-British National Formulary. London: BMJ Group \& RPS Press; 2009

32. Comer AM, Figgitt DP. Sertraline. CNS Drugs. 2000;14:391-407.

33. Amalesh S, Debprasad C, Chandrima S, Ananda DJ, Soma G, Anurup M, et al. Evaluation of in vivo and in vitro antimicrobial activities of a selective Serotonin reuptake inhibitor Sertraline Hydrochloride. Anti-Infect Agents. 2012;10:95-104

34. Barrow Gl, Feltham RKA. Cowan and steel's manual of the identification of medical bacteria. Cambridge: Cambridge University Press; 1993.

35. Wikler MA. Performance standards for antimicrobial susceptibility testing seventeenth informational supplement: Clinical and Laboratory Standards Institute; 2007. 
36. CLSI. Methods for dilution antimicrobial susceptibility tests for bacteria that grow aerobically; Approved standard. 9th Edition. Wayne, PA: Clinical and Laboratory Standards Institute; 2012.

37. Richard S, Lynn SM, Avery CG. Antimicrobial susceptibility testing protocols. New York: CRC Press; 2007.

38. Petrikkou E, Rodríguez-Tudela JL, Cuenca-Estrella M, Gómez A, Molleja A, Mellado E. Inoculum standardization for antifungal susceptibility testing of filamentous fungi pathogenic for humans. J Clin Microbiol. 2001;39:1345-7.

39. Cederlund H, Mårdh PA. Antibacterial activities of non-antibiotic drugs. J Antimicrob Chemother. 1993;32:355-65.

40. Cheesbrough M. Medical laboratory manual for tropical countries. 2nd ed. Cambridge: Butterworth-Heinemann; 1987.

41. Roberts WK, Selitrennikoff CP. Plant and bacterial chitinases differ in antifungal activity. J Gener Microbiol. 1988;134:169-76.

42. Allen KL, Molan PC, Reid GM. A survey of the antibacterial activity of some New Zealand honeys. J Pharm Pharmacol. 1991;43:817-22.

43. Cruickshank R, Duguid JP, Swain RHA. Medical microbiology. A guide to the laboratory diagnosis and control of infection. 1965.

44. National Committee for Clinical Laboratory Standards. Approved standard M7-A3. 3rd ed. PA: NCCLS, Villanova; 1993.

45. National Committee for Clinical Laboratory Standards. Approved standard M2-A5. 5th ed. PA: NCCLS, Villanova; 1993.

46. Performance standards for antimicrobial susceptibility testing. CLSI document M100-S18. Clinical and Laboratory Standards Institute W: PA; 2008.

\section{Submit your next manuscript to BioMed Central and take full advantage of:}

- Convenient online submission

- Thorough peer review

- No space constraints or color figure charges

- Immediate publication on acceptance

- Inclusion in PubMed, CAS, Scopus and Google Scholar

- Research which is freely available for redistribution 